\title{
The Antarctic Circumpolar Current as a diversification trigger for deep-sea octocorals
}

\author{
Luisa F. Dueñas ${ }^{1,2^{*}}$, Dianne M. Tracey ${ }^{3}$, Andrew J. Crawford ${ }^{1,4}$, Thomas Wilke², Phil Alderslade $^{5}$ \\ and Juan A. Sánchez ${ }^{1,2}$
}

\begin{abstract}
Background: Antarctica is surrounded by the Antarctic Circumpolar Current (ACC), the largest and strongest current in the world. Despite its potential importance for shaping biogeographical patterns, the distribution and connectivity of deep-sea populations across the ACC remain poorly understood. In this study we conducted the first assessment of phylogeographical patterns in deep-sea octocorals in the South Pacific and Southern Ocean, specifically a group of closely related bottlebrush octocorals (Primnoidae: Tokoprymno and Thourella), as a test case to study the effect of the ACC on the population structure of brooding species. We assessed the degree to which the ACC constitutes a barrier to gene flow between northern and southern populations and whether the onset of diversification of these corals coincides with the origin of the ACC (Oligocene-Miocene boundary).
\end{abstract}

Results: Based on DNA sequences of two nuclear genes from 80 individuals and a combination of phylogeographic model-testing approaches we found a phylogenetic break corresponding to the spatial occurrence of the ACC. We also found significant genetic structure among our four regional populations. However, we uncovered shared haplotypes among certain population pairs, suggesting long-distance, asymmetrical migration. Our divergence time analyses indicated that the separation of amphi-ACC populations took place during the Middle Miocene around 12.6 million years ago, i.e., after the formation of the ACC.

Conclusion: We suggest that the ACC constitutes a semi-permeable barrier to these deep-sea octocorals capable of separating and structuring populations, while allowing short periods of gene flow. The fluctuations in latitudinal positioning of the ACC during the Miocene likely contributed to the diversification of these octocorals. Additionally, we provide evidence that the populations from each of our four sampling regions could actually constitute different species.

Keywords: Antarctic Circumpolar Current, Gene flow, Primnoid octocorals, Southern Ocean, Deep-sea, Statistical phylogeography

\section{Background}

Despite our growing understanding of the role of Antarctica in driving global climate regimes and regional patterns of marine diversity, the distribution and connectivity among deep-sea benthic populations across the Southern Ocean remain poorly known. This vast and

\footnotetext{
* Correspondence: If.duenas161@uniandes.edu.co

1 Department of Biological Sciences, Universidad de los Andes, A.A. 4976 Bogotá, Colombia

${ }^{2}$ Department of Animal Ecology \& Systematics, Justus Liebig University, Giessen, Germany

Full list of author information is available at the end of the article
}

remote region of the globe hosts a surprising diversity of organisms [1] that thrive under extreme environmental conditions. While many of the Southern Ocean species from shallower continental shelves were discovered and described in the early 20th Century [2], exploration vessels with state-of-the-art underwater equipment are now sampling deep-sea regions. Molecular methods have also aided tremendously in the discovery of new species and the inference of their evolutionary origins and population genetic structure [3, 4]. Despite this increased exploration, only an estimated one-quarter of the continental shelf 
fauna has been described $[5,6]$, and most deep-sea regions have never been explored. Consequently, more research is needed on these deep-sea frontiers in order to assess faunal diversity and endemism, and to understand the origin, distribution and maintenance of deep-sea populations in the Southern Ocean.

The Antarctic continent and its attending Southern Ocean are surrounded by the Antarctic Circumpolar Current (ACC), the largest and strongest current in the world [7]. The onset of the ACC is thought to have occurred at the Oligocene-Miocene boundary around 25 million years ago (Ma), when South America separated from Antarctica creating the Drake Passage [8]. The ACC is characterized by an extreme transition of temperature and by profound depths of over $1000 \mathrm{~m}$; in some places even extending to the seabed at a depth of $4000 \mathrm{~m}$ [9]. The particular oceanographic conditions of the ACC likely promoted the biogeographic isolation of the Southern Ocean [10] by creating a natural marine barrier to genetic exchange [7]. Some marine benthic organisms are distributed across the ACC, however, suggesting some level of permeability and potential gene flow [11-13]. Therefore, the ACC could represent a distinctive biogeographical discontinuity, where few marine benthic organisms occur both north and south of this current [14]. Nevertheless, at present it remains unclear what factors determine whether the ACC acts as a strong barrier against gene flow for some organisms and yet remains permeable to others.

Gene flow is governed by the interaction of extrinsic environmental factors with intrinsic factors determined by the natural history of each species [15]. In the case of marine organisms, extrinsic factors such as light, temperature, $\mathrm{pH}$ and of course currents may promote or impede larval dispersal. Using oceanographic data, Clarke et al. [14] identified turbulent flow structures, called eddies, over a wide range of scales in the ACC. These eddies can have warm-core or cold-core rings, transporting water and larvae from sub-Antarctic to Antarctic waters, and vice versa. Anthropogenic mechanisms could also carry organisms across the ACC, e.g., increasingly frequent ship transport that may carry encrusting organisms on their hulls or free-swimming organisms in ballast waters [16]. Factors intrinsic to the life history of marine organisms may also determine levels of gene flow, especially those traits related to dispersal ability [10], e.g., brooder versus broadcast spawners. The latter go through a pelagic larval stage that can span from a few days to several months [17], facilitating possible long-distance dispersal. In contrast, brooders incubate their larvae that then settle and metamorphose at short distances from their parents $[17,18]$. Given such variation in reproductive strategies and developmental mode among benthic invertebrates, we expect that with a decreasing length of the pelagic larval phase (or for brooder species without pelagic larvae), there will be an increase in genetic differentiation $[19,20]$.

One brooding deep-water taxon occurring across the ACC (Fig. 1) is the bottlebrush-like octocoral, Tokoprymno maia Bayer [21] (Octocorallia: Primnoidae). Tokoprymno maia was originally described from sub-Antarctic waters (southeastern Pacific Basin, 54.49' S $129^{\circ} 48^{\prime} \mathrm{W}$ ) at a depth of $549 \mathrm{~m}$ [21] but is widely distributed in the southern Pacific Ocean. Recent deep-sea voyages have also located this species on seamounts around New Zealand and south of Tasmania (Australia) at depths of $350 \mathrm{~m}$ to $1700 \mathrm{~m}$ (Fig. 2). Preliminary morphological and genetic analyses, part of which will be shown in this study, indicate that this primnoid octocoral could comprise a complex of species that includes nominal T. maia as well as populations from another taxonomic unit from sub-Antarctica. The later closely resembles a species of the sister genus Thouarella Gray, 1870 [22]; namely T. viridis Zapata-Guardiola and López-González, (2010) (Dueñas et al., unpublished observations). However, there are a few differences between $T$. viridis and our Thouarella-like samples, namely: sculpturing on the surface of the coenenchmal sclerites; the colour of the colonies; and the distribution, as T. viridis has only been reported from the sub-Antarctic waters in the South Atlantic. Nevertheless, despite the morphological differences between T. maia and the Thouarella-like colonies, our molecular analyses clearly show that they share haplotypes. Therefore, we consider them to be closely related to the T. maia samples used in this study and they will be treated as part of a complex that will be referred to in the text as the primnoid bottlebrush octocorals'. Data presented below support this simplifying hypothesis. A manuscript formally addressing this taxonomic puzzle will follow.

In this study we use these particular primnoid bottlebrush corals as a test case to assess the effect of the world's largest and strongest ocean current on the population structure of brooding amphi-ACC species. Our specific questions are:

1) Does the ACC constitute a barrier to gene flow between northern and southern populations? Our null hypothesis is that the ACC does not currently act as a barrier, resulting in a panmictic population with no genetic structure between localities. This prediction will be tested through phylogeographical analyses of multiple a priori migration models.

2) If the former hypothesis is rejected, does the origin of the ACC during the Oligocene-Miocene boundary coincide with the onset of diversification within the primnoid bottlebrush corals? Our null hypothesis is that the ACC constitute an old barrier, in which case the onset of divergence between populations north and south of the current should corresponded to the 


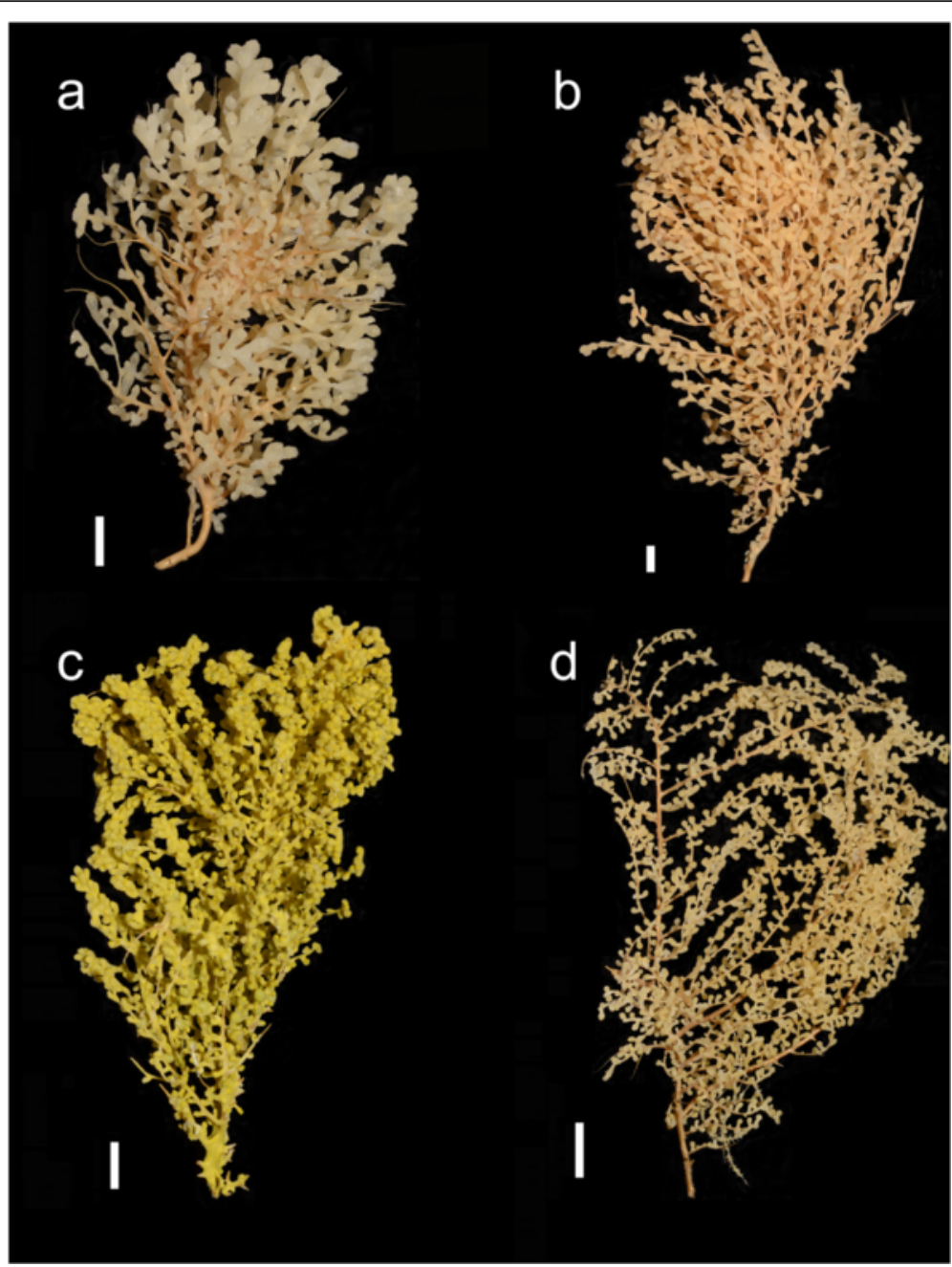

Fig. 1 Photographs of the bottlebrush deep-sea octocoral colonies from the South Pacific and Southern Ocean. Each letter represents an example of the colonies from each population: a- New Zealand, b- Tasmania, c- Macquarie Ridge, $\mathbf{d}$ - Antarctica. The bar next to each colony corresponds to a $1 \mathrm{~cm}$ scale

approximate date of the onset of the ACC around $25 \mathrm{Ma}$. This prediction will be tested using a molecular clock approach.

Assessing the mechanisms underlying the population genetic structure of deep-sea species could help shed light on the role of marine barriers as diversification triggers and how connectivity is maintained in marine populations, particularly across large biogeographic features such as the ACC.

\section{Results}

\section{Phylogenetic analyses}

DNA samples from 80 specimens were successfully amplified and sequenced for two rDNA nuclear regions: the internal transcribed spacer 2 (ITS2) and 28S. The data matrix had a total of 927 characters from which 497 were parsimony-informative.
Topologies inferred using Maximum Likelihood (ML) and Bayesian Inference (BI) were nearly identical, with some variation in support values. Figure 3 displays the resulting unrooted and mid-point rooted topologies. The phylogeny showed a basal split of lineages across the ACC, corresponding to southern samples (Clade I) and northern samples (Clades II-IV). We inferred four wellsupported clades, where Clade I contained only samples from Antarctica (Fig. 3). Clade II contained mainly samples from New Zealand, plus five from Antarctica and two from Tasmania. Clade III contained only samples from Tasmania. Finally, Clade IV was comprised exclusively of samples from the Macquarie Ridge, a long seamount chain south of New Zealand (Fig. 2).

Both rDNA gene regions showed substantial amongindividual variation when applied to the study of deep-sea bottlebrush octocorals, but no evidence of intra-individual variation. $28 \mathrm{~S}$ showed genetic divergences within clades 

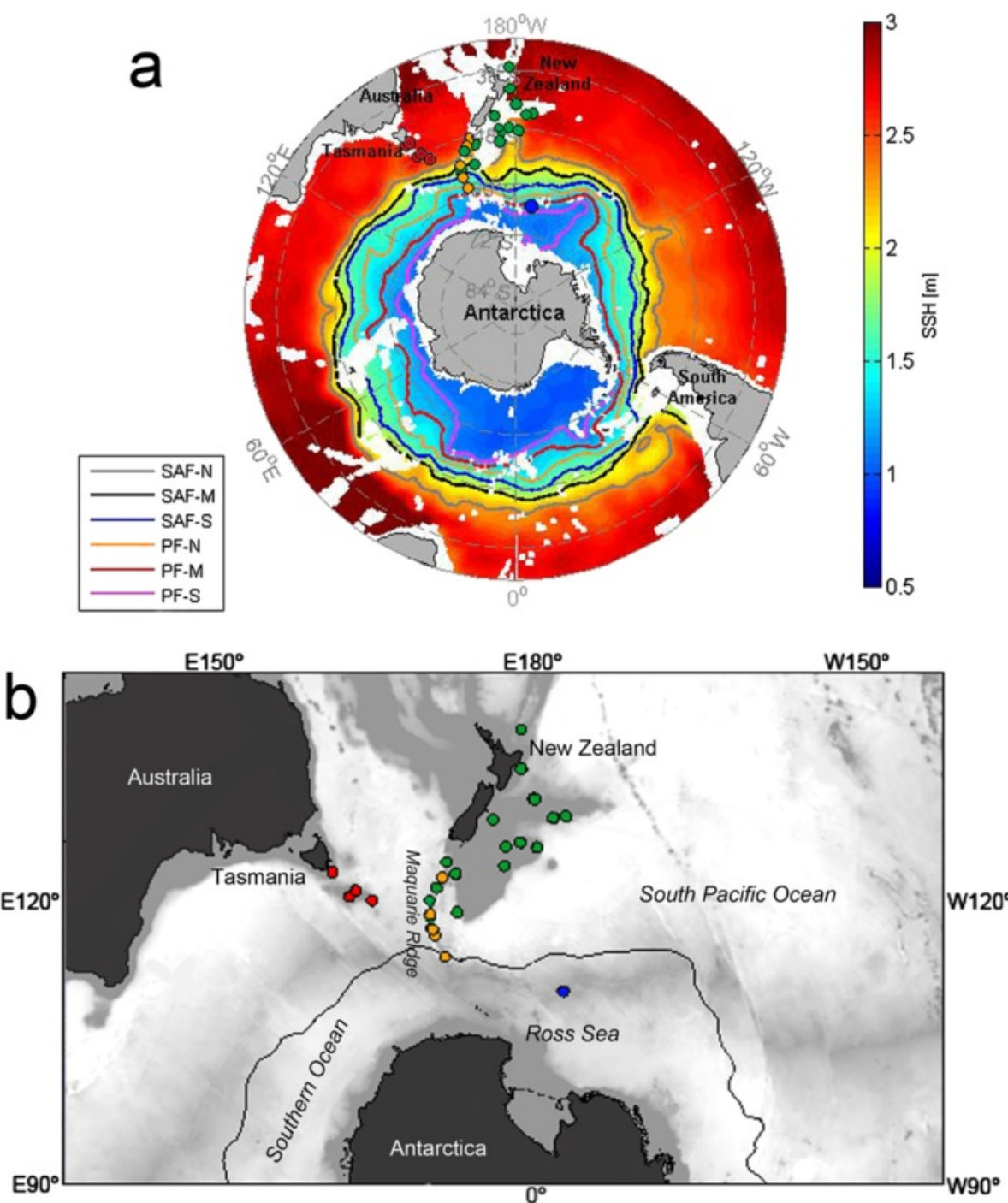

Fig. 2 Geographic distribution of samples of bottlebrush deep-sea octocorals from the South Pacific and Southern Ocean. Samples from Tasmania are shown in red, samples from New Zealand in green, samples from the Macquarie Ridge in orange, and samples from Antarctica in blue. a- ACC front positions mapped using Sea Surface Height (SSH) overlaying Southern Ocean mean SSH. Fronts showed are sub-Antarctic Front (SAF-N, SAF-M, SAF-S); Polar Front (PF-N, PF-M, PF-S); -N, northern branch; -M, middle branch; -S, southern branch. Fronts are identified by their SSH signal following the methods described in Sokolov and Rintoul [108]. Blank spaces indicate bathymetry shallower than $2500 \mathrm{~m}$. b- Zoom on the localities from this study. In this case bathymetry is shown in grey tones, where darker ones represent shallower waters. The black line surrounding Antarctica shows the position of the Polar Front

ranging from 0.03 to $6.79 \%$ (uncorrected p-distances), and between clades from 3.97 to $18.47 \%$. ITS2 showed higher pairwise distances in comparison to $28 \mathrm{~S}$, i.e., within-clade distances ranging from 0.17 to $3.00 \%$ and between-clade distances from 4.98 to $33.55 \%$. Total genetic divergences based on concatenating the two nuclear loci ranged from 0.1 to $6.1 \%$ within clades and from 1.9 to $19.1 \%$ between clades.

\section{Phylogeographical analyses}

Using the Bayes Factor approach we found that the fourpopulation model had the highest marginal likelihood
(Additional file 1) as estimated by thermodynamic integration, thus supporting the phylogenetic premise of separating the Macquarie Ridge population from the New Zealand population. Therefore, we recognized Tasmania, Antarctica, New Zealand and the Macquarie Ridge as four distinct populations for all posterior analyses.

The haplotype relationships show the same clades as in the inferred phylogenetic tree (Fig. 4). There are four main clades, where Clade I has four haplotypes all from Antarctica. Clade II, composed mainly of samples from New Zealand, has a main dominant haplotype shared with Antarctica and other closely related haplotypes 


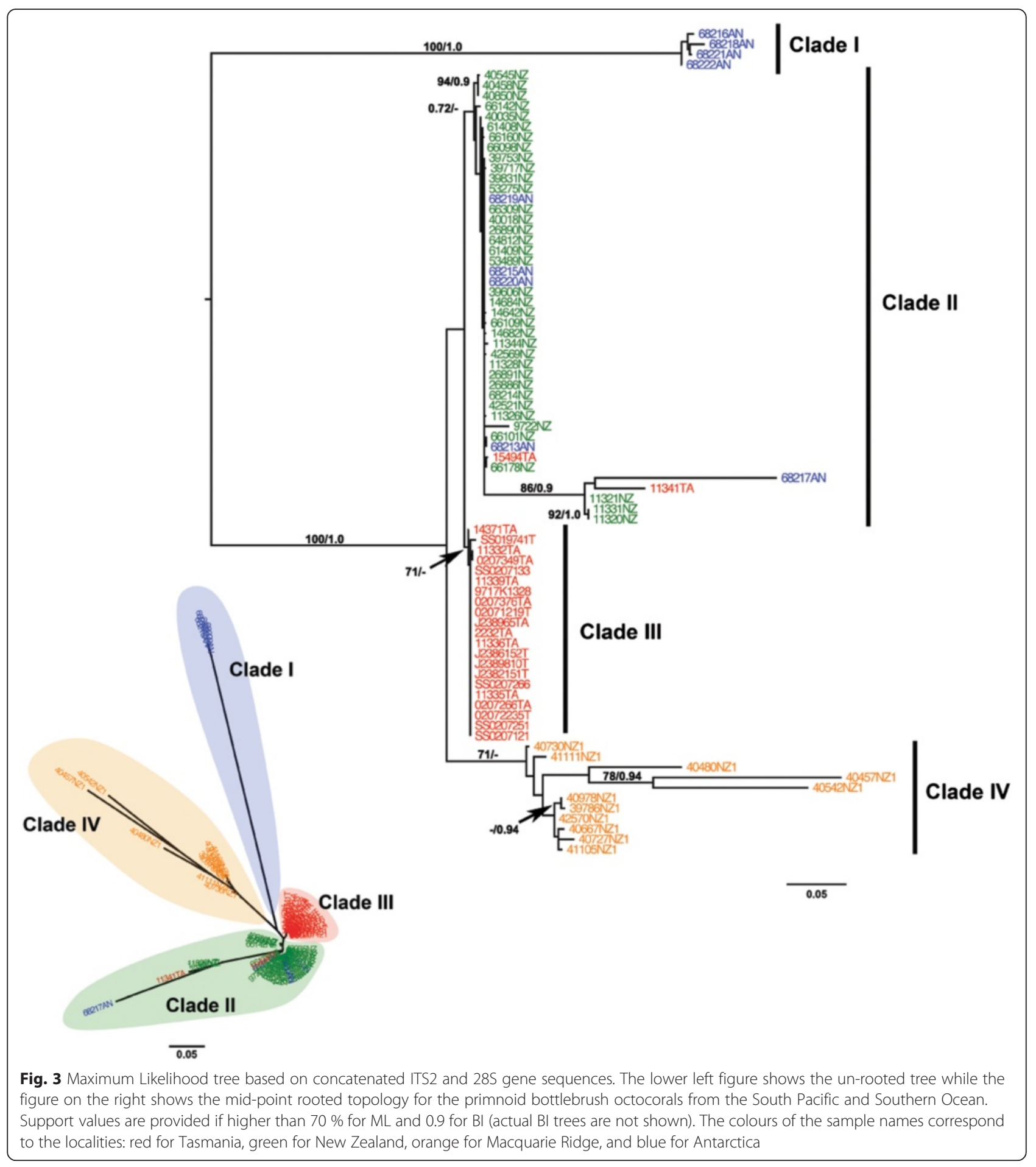

from Antarctica and Tasmania. Clade III is represented by one dominant haplotype, composed exclusively by samples from Tasmania. Finally, Clade IV is represented exclusively by individuals from the Macquarie Ridge where there are no dominant haplotypes (Fig. 4).

Preliminary population genetic analyses showed that Hd and $\theta_{\mathrm{W}}$ were higher in Antarctica and the Macquarie
Ridge (Table 1). Nucleotide diversity was highest in Antarctica, with New Zealand and Tasmania showing the lowest value of 0.01 (Table 1). The AMOVA that grouped all localities as one population (i.e., no ACC barrier) showed that the percentage of variation among localities is slightly higher $(56.50 \%)$ than within localities, with significant structure $\left(F_{\mathrm{ST}}=0.57, P<0.001\right)$. On the other 


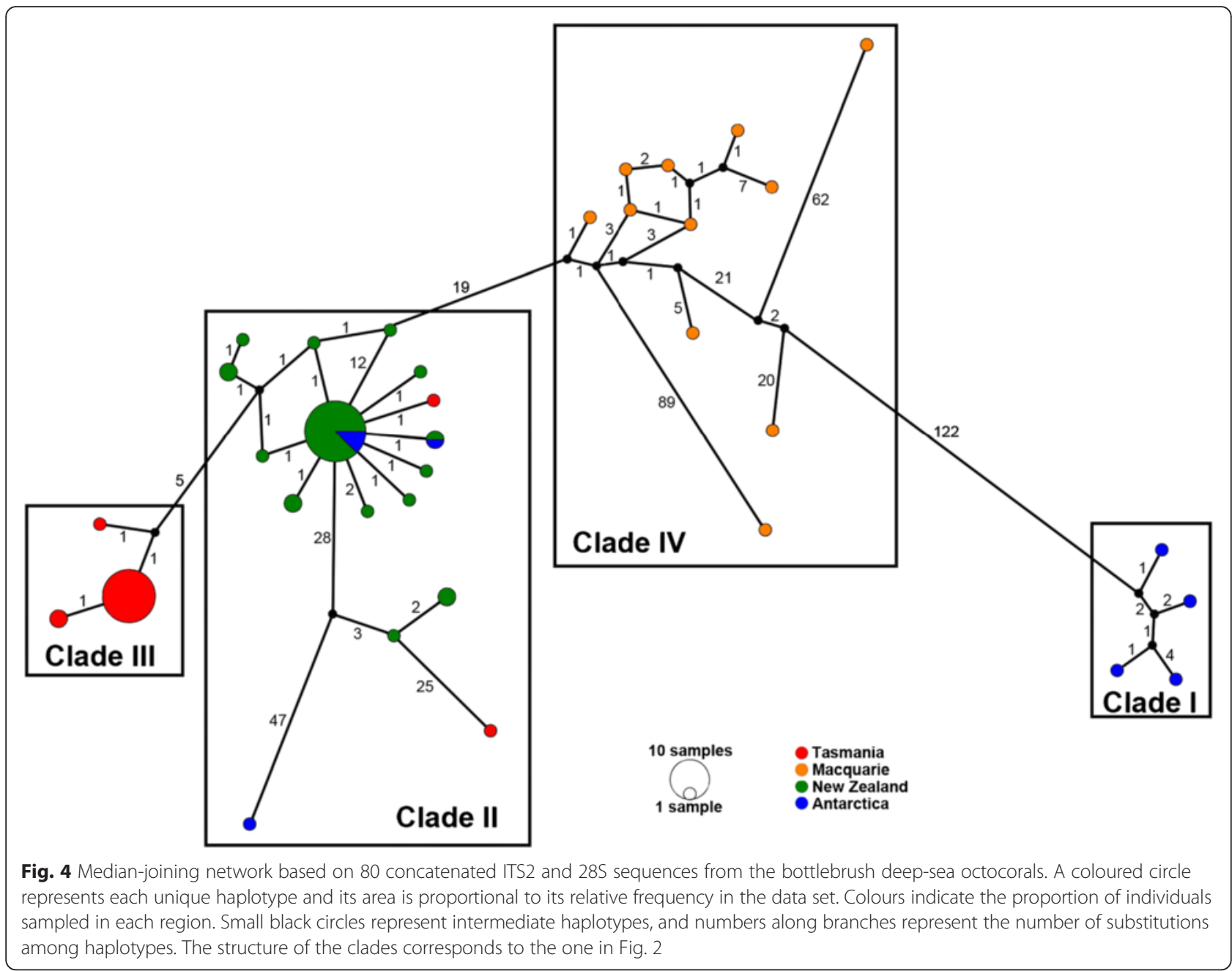

hand, the AMOVA that assumed that the sub-Antarctic localities (Tasmania, New Zealand, and Macquarie Ridge) were one population (i.e., ACC as a barrier) also indicated a significant population structure $\left(F_{\mathrm{ST}}=0.61, P<0.001\right)$ across the ACC, with substantial variation partitioned among localities within populations (47.17\%; Table 2). Pairwise $F_{\mathrm{ST}}$ analyses showed significant population structure between all pairs of localities, with the most

Table 1 Genetic polymorphisms within populations of the bottlebrush octocorals from the South Pacific and Southern Ocean

\begin{tabular}{llllll}
\hline Population & $\mathrm{n}$ & $\mathrm{h}$ & $\mathrm{Hd}$ & $\pi$ & $\theta \mathrm{w}$ \\
\hline Tasmania & 23 & 6 & 0.46 & 0.01 & 0.03 \\
Macquarie Ridge & 11 & 11 & 1.00 & 0.06 & 0.08 \\
New Zealand & 37 & 14 & 0.68 & 0.01 & 0.02 \\
Antarctica & 9 & 7 & 0.92 & 0.13 & 0.10
\end{tabular}

The variables in the table represent: number of samples (n), number of haplotypes (h), haplotype diversity $(\mathrm{Hd})$, nucleotide diversity per site $(\pi)$, Watterson's estimate of the population mutation rate per site $\left(\theta_{\mathrm{W}}\right)$ marked population structure found between Tasmania and Macquarie $\left(F_{\mathrm{ST}}=0.61, P<0.001\right)$, and the smallest between Antarctica and Macquarie $\left(F_{\mathrm{ST}}=0.31, P<0.001\right.$; Table 3).

Among eight distinct spatial migration models, two were highly supported by our log Bayes Factor (LBF) analyses: asymmetric migration from north to south (Model IV) and a stepping-stone model (Model VI), (Table 4). The worst two models both assumed that the ACC was a barrier (Model VII and Model VIII), i.e., Antarctica was isolated from the sub-Antarctic populations (Table 4).

MIGRATE-N reports mutation-scaled migration rates $(M=m / \mu)$, where $m$ is immigration rate per generation and $\mu$ the mutation rate. The mutation-scaled migration rate represents the importance of within-population variation derived from migration events relative to mutation [23]. In the absence of reliable estimates of $\mu$ for ITS2 and $28 \mathrm{~S}$ in octocorals, we graphically present estimates of the relative values of $M$, where the arrows show the direction of migration events and the thickness is proportional to 
Table 2 Analysis of Molecular Variance (AMOVA) implemented in Arlequin 3.5.1.3 [91]

\begin{tabular}{|c|c|c|c|c|c|c|c|}
\hline Source of variation & d.f. & Sum of squares & Variance components & Percentage of variation & $F_{S C}$ & $F_{S T}$ & $F_{C T}$ \\
\hline Among localities & 3 & 1345.80 & 24.01 & 56.50 & & & \\
\hline Within localities & 76 & 1404.52 & 18.48 & 43.50 & & & \\
\hline Total & 79 & 2750.31 & 42.49 & & & $0.57^{* * *}$ & \\
\hline Among populations & 1 & 366.82 & 6.31 & 13.44 & & & \\
\hline Among localities within populations & 2 & 978.97 & 22.13 & 47.17 & & & \\
\hline Within localities & 76 & 1404.52 & 18.48 & 39.39 & & & \\
\hline Total & 79 & 2750.31 & 46.92 & & $0.55^{* * *}$ & $0.61^{* * *}$ & 0.13 \\
\hline
\end{tabular}

Four localities (Tasmania, Macquarie Ridge, New Zealand and Antarctica) of the primnoid bottlebrush octocorals from the South Pacific and Southern Ocean were assessed. The top section evaluates a grouping in which all collecting localities are part of one unique population (i.e., ACC as no barrier), while the bottom section evaluates a scenario in which the sub-Antarctic localities are grouped as one population (Tasmania, Macquarie Ridge, and New Zealand) compared to Antarctica (i.e., ACC as a barrier)

*** indicates $P<0.001$

the mutation-scaled migration rate (Fig. 5). Unidirectional migration rates were highest from New Zealand to Tasmania, from New Zealand to Antarctica, and from Antarctica to Tasmania. The lowest estimates were from Tasmania to the Macquarie Ridge, and from New Zealand to the Macquarie Ridge. Estimates and attending confidence intervals around $M$ are given in Additional file 2.

\section{Divergence time estimation and ancestral character state reconstruction}

The stem age of bottlebrush octocorals was estimated at 13.7 Ma (95 \% credible interval [C.I.] of 6.6-20.3 Ma) and the divergence between Antarctica and the northern populations (crown age) took place during the Middle Miocene 12.6 Ma (95 \% C.I. 5.6-20.2 Ma; Fig. 6). Populations in the Macquarie Ridge separated from those in Tasmania and New Zealand around 5.5 Ma (95 \% C.I. 1.6-10.9 Ma), and finally populations from Tasmania and New Zealand separated from each other around $1.8 \mathrm{Ma}$ (95 \% C.I. 0.7-3.9 Ma).

The ancestral area reconstruction was largely unresolved. Both the maximum likelihood reconstruction and the stochastic mapping showed probabilities of roughly 0.25 for each possible state at the ancestral node (Node A; Additional files 1, 3 and 4). Node B, the common ancestor

Table $3 F_{S T}$ values for pairwise comparisons among populations of primnoid bottlebrush deep-sea octocorals

\begin{tabular}{lllll}
\hline & Tasmania & $\begin{array}{l}\text { Macquarie } \\
\text { Ridge }\end{array}$ & $\begin{array}{l}\text { New } \\
\text { Zealand }\end{array}$ & Antarctica \\
\hline Tasmania & - & - & - & - \\
Macquarie Ridge & $0.61^{* * *}$ & - & - & - \\
New Zealand & $0.49^{* * *}$ & $0.59^{* * *}$ & - & - \\
Antarctica & $0.36^{* * *}$ & $0.31^{* * *}$ & $0.35^{*}$ & - \\
\hline
\end{tabular}

Comparisons based on concatenated ITS2 and $28 \mathrm{~S}$ gene sequences. Sample sizes are given in Table 1

${ }^{*} 0.01<P<0.05$; ${ }^{* * *} P<0.001$ of Macquarie Ridge plus New Zealand, showed a similarly ambiguous pattern under either reconstruction methods. Finally, for Node C, the common ancestor of Tasmania plus New Zealand, the highest probability was for a Tasmanian ancestor (Additional files 3, 4 and 5).

\section{Discussion}

This study represents the first attempt to explore the roll of the ACC as a potential barrier to gene flow in deep-sea octocorals from the Southern Pacific Ocean and Southern Ocean. The phylogenetic analyses strongly suggest a phylogenetic break between amphi-ACC populations. Finding two distinct, reciprocally monophyletic clades in the vicinity of New Zealand was wholly unexpected. The diversification of the bottlebrush deep-sea octocorals was estimated at 6.6-20.3 Ma, well after the formation of the ACC at $25 \mathrm{Ma}$. Thus, the initial isolation of Antarctic populations was likely driven by other oceanographic changes during the Middle Miocene, or else the process of isolation by the ACC perhaps took some ten million years. Despite the high genetic structuring among our four regional populations, we uncovered shared haplotypes among certain population pairs, suggesting long-distance migration. Recent migration between populations north and south of the ACC was also seen, where population genetics analyses revealed a complex scenario of isolation with asymmetric gene flow. Consequently, the ACC has not served as an impermeable gene flow barrier for these brooder corals.

\section{The ACC as a barrier to gene flow}

The phylogenetic analyses revealed deeply structured geographic clades, combined with some clear cases of haplotype sharing, particularly between New Zealand and Tasmania, as well as between New Zealand and Antarctica. These migrant individuals were independently extracted, PCR amplified and sequenced multiple times in separate laboratories to rule out contamination as an 
Table 4 MIGRATE-N [23] runs showing the log-probability of the data given the model (marginal likelihood) for the following migration models: I) full migration between the four localities; II) migration from West to East; III) migration from East to West; IV) migration from North to South; V) migration from South to North; VI) a stepping-stone model; VII) ACC as a permanent barrier between north and south populations, with full migration between northern populations; VIII) ACC as a permanent barrier and stepping-stone between northern populations

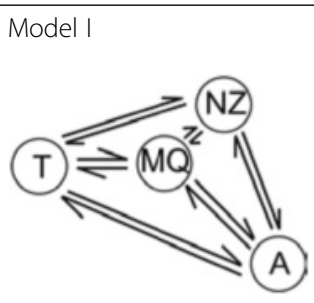

No. Parameters

Specification

Bezier ImL

LBF

Choice

Posterior Prob.
16

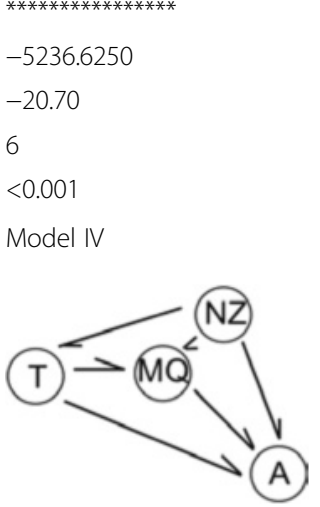

10

${ }^{*} 0 * 0 * * * 000 * 0$ ****

$-5216.5184$

$-0.59$

2

0.36

Model VII

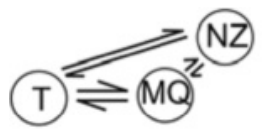

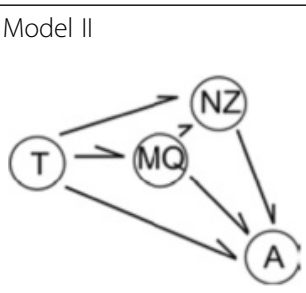

10

${ }^{*} 000 * * 00 * * * 0 * * *$

$-5223.4028$

$-7.48$

4

$<0.001$

Model V

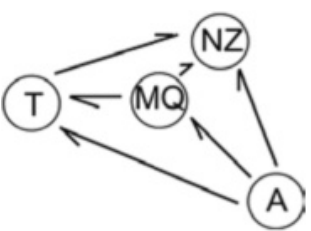

10

${ }^{* *} 0^{*} 0^{*} 0^{* * * * *} 000^{*}$

$-5223.9708$

$-8.05$

5

$<0.001$

Model VIII

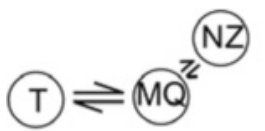

Model III

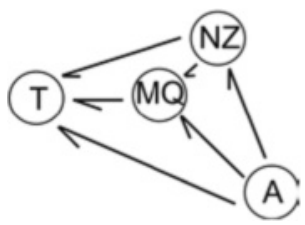

10

****0***0 $00^{* *} 000$ *

$-5221.5584$

$-5.63$

3

$<0.01$

Model VI

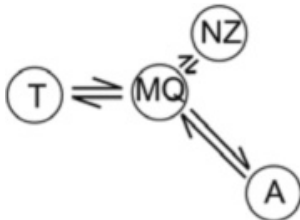

10

${ }^{* *} 00^{* * * *} 0^{* *} 00^{*} 0 *$

$-5215.9249$

0.00

1

0.64

\section{(A)}

(A)

$\begin{array}{ll}\text { No. Parameters } & 10 \\ \text { Specification } & * * * 0^{* * *} 0^{* * *} 0000^{*} \\ \text { Bezier ImL } & -5930.9088 \\ \text { LBF } & -714.98 \\ \text { Choice } & 7 \\ \text { Posterior Prob. } & <0.0001\end{array}$

8

${ }^{* *} 00 * * * 00 * * 0000$ *

$-6300.2584$

$-1084.33$

8

$<0.0001$

The first row represents the number of parameters used for a particular model. The second row shows the symbol specification for the migration matrix given to MIGRATE-N where and asterisk represents an estimated parameter and a zero a non-estimated parameter. The third row provides the log marginal likelihood for each model obtained by thermodynamic integration. The forth row reports the log Bayes Factor (LBF). The row 'Choice' orders the models based on the LBF, and finally, the sixth row shows the probability for each model. Populations are labelled as follows: T for Tasmania, MQ for Macquarie Ridge, NZ for New Zealand, and A for Antarctica 


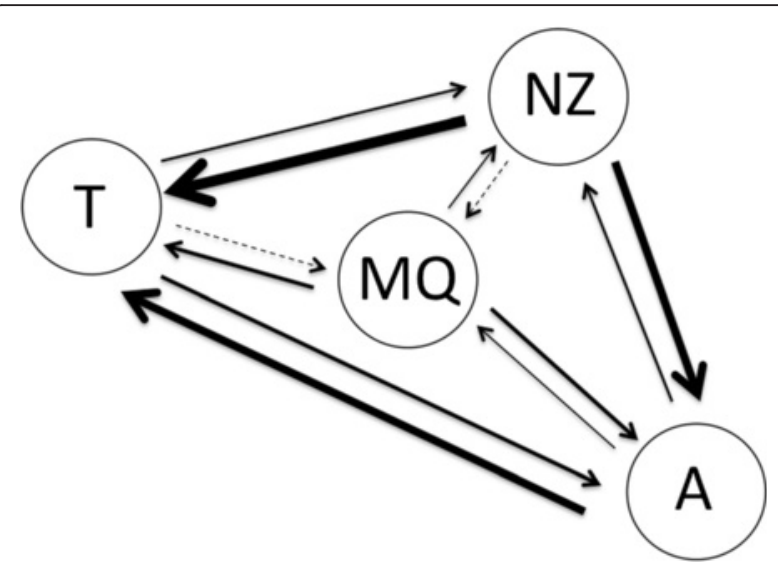

Fig. 5 Graphical summary of relative unidirectional migration rates estimated from the best-supported model of population structure. The arrows show the estimates for the direction of migration between populations of the primnoid bottlebrush octocorals from the South Pacific and Southern Ocean, and the thicknesses are proportional to the mutation-scaled migration rate (M). Populations are labelled as follows: T for Tasmania, MQ for Macquarie Ridge, NZ for New Zealand, and $\mathrm{A}$ for Antarctica

explanation. Thus, our data clearly demonstrate migration events between these localities, probably more recent than 100 thousand years ago (Ka). Additional analyses using multilocus coalescent approaches would be useful to infer the exact age of such recent events, and, although this is not the scope of this study, we do know that since $30 \mathrm{Ka}$ the Southern Ocean regime has fluctuated dramatically. Any of these oceanographic fluctuations may have promoted dispersal by brooding octocorals among our four populations. Bostock et al. [24] used microfossil assemblages to assess the change in oceanographic features and showed shifts in sea surface temperatures (SST), position of the major fronts of the ACC (the Sub-Antarctic Front or SAF, and the Polar Front or PF), velocity of deep (lower Circumpolar Deep Water) and intermediate (the Antarctic Intermediate Water or AAIW) water masses, among other major oceanographic events that occurred since the Last Glacial Maximum (LGM) up to the establishment of the current oceanographic regime around $10 \mathrm{Ka}$. The AAIW is particularly interesting in the present context, given that it flows at intermediate depths of approximately 700 to $1300 \mathrm{~m}$ [25], in a similar depth range as the collection sites of the samples analysed here (443-1712 m). Bostock et al. [24] defined the LGM for the Australian-New Zealand Southern Ocean region as having occurred from 21 to $18 \mathrm{Ka}$. During the most recent interglacial and LGM (30-18 Ka) the trajectory of the ACC (including STF, SAF, and PF) was located north of the current position [26], and the strength of the AAIW increased, flowing from north to south and vice versa [24]. Additionally, the Campbell Gyre intensified, which allowed a deep mixing of waters over the Campbell Plateau coupled with strong flow that reached the Chatham Rise [26, 27]. Both the Campbell Plateau and Chatham Rise host high abundances of T. maia. Additional evidence based on actual and LGM species distribution models suggests that the Tasman and Campbell Plateau, as well as other subAntarctic areas, were suitable as potential refuges during the LGM for the deep-sea shrimp Nematocarcinus lanceopes, restricting these Antarctic benthic organisms to higher latitudes [28]. Rapid changes in flow trajectories and intensities of the currents may have allowed higher connectivity among populations during the LGM, as evidenced by the presence of shared haplotypes between some distant populations.

While recent migration is indicated by shared haplotypes, we found high population divergence between northern and southern localities, clearly suggesting a barrier. On the other hand, the two least supported migration models were the ones that hypothesized an ACC barrier. Migration analyses would seem to suggest no barrier, but it is important to see barriers as a continuum [29]. This continuum is determined by physically and ecologically mediated disruptions in the range of a species. Within this continuum, 'hard' barriers are single physical features where dispersal is nil or very infrequent, and 'soft' barriers are general regions that experience climatic oscillations or exhibit ecological gradients where dispersal is not uncommon [29]. Soft barriers can also be seen as 'filters' acting only on selected species rather than impassable absolute barriers [30]. We thus conclude that the ACC is a 'soft barrier' that has suffered oscillations in position and velocity of some of its associated fronts and currents throughout its history. The ACC also exhibits environmental gradients in temperature and salinity in each front. Therefore, the ACC is capable of separating and structuring primnoid bottlebrush octocoral populations, while allowing bursts of limited gene flow.

Antarctica's closest continental neighbor is South America, where the Antarctic Peninsula and Patagonia are separated by the Drake Passage, a channel that spans just $900 \mathrm{~km}$ with a depth of $4500 \mathrm{~m}$ [31]. This particular point has received considerable attention in biogeographical studies because of the short geographic distance between continental platforms, the common geological origin, and the presence of shared species (e.g., [1, 12, 32-34]). However, the ACC clearly acts as a barrier to gene flow for other species, such as the bottlebrush octocorals studied here, along with benthic organisms of several phyla, including brooding and spawning species, and deep- and shallow-water species $[4,10-13]$. In some cases, samples from Antarctica and South America are highly diverged showing reciprocal monophyly, which suggests isolation, lack of gene flow between northern and southern populations as well as potentially cryptic speciation [10], as found here for brooder bottlebrush octocorals. 


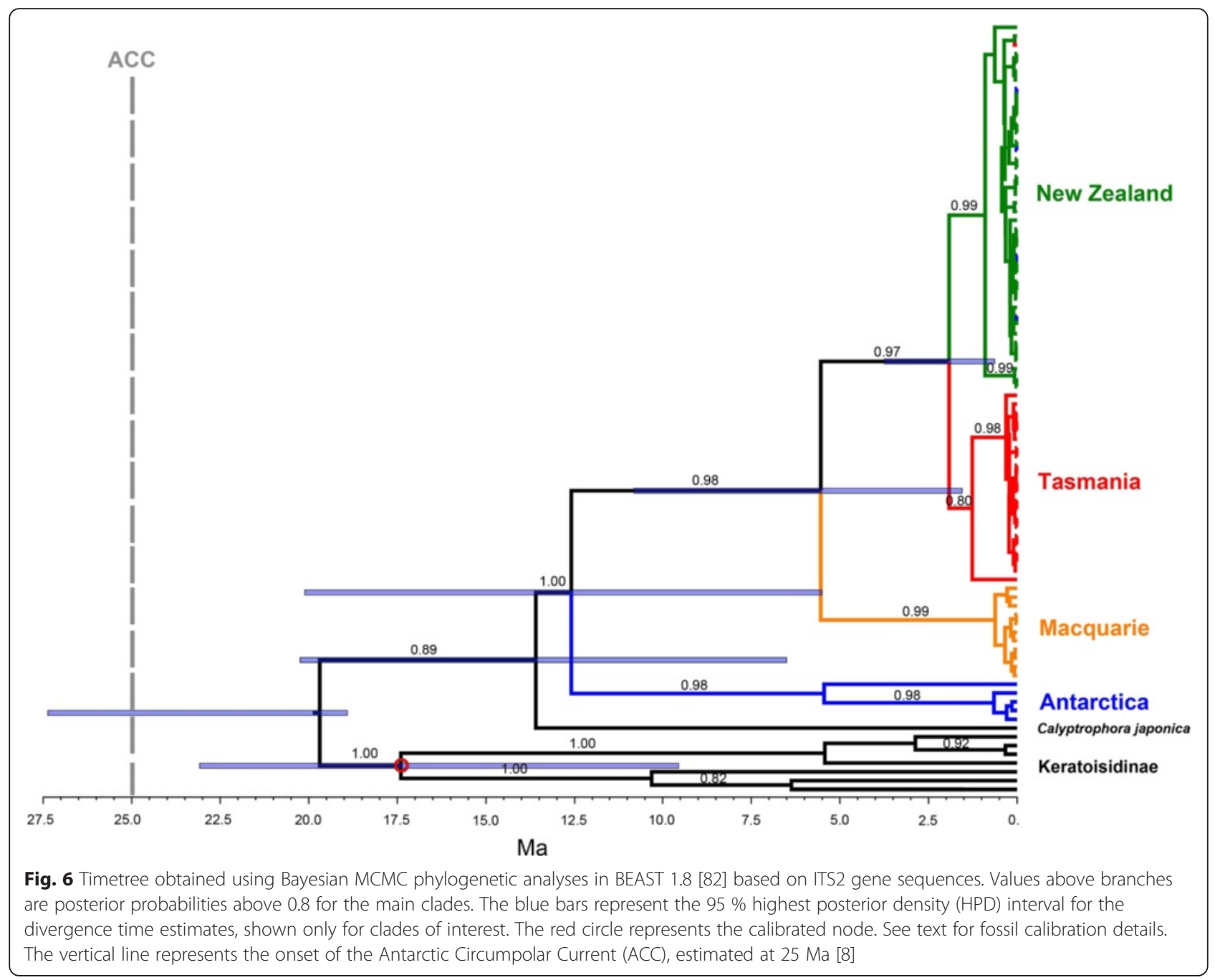

\section{Onset of the ACC versus time of diversification of the primnoid bottlebrush octocorals}

The phylogenetic analyses show the population from Antarctica as the earliest divergent lineage, which is also the population with the highest genetic diversity. While source populations are often expected to have higher genetic diversity [35], using comparative methods we could not find support for any particular population being the ancestor. The origin of the ACC, dated around $25 \mathrm{Ma}$ [8], likely did not drive the basal split of T. maia, which took place at some point during the Miocene (6.6-20.3 Ma), unless the process was particularly slow. A more likely driver of diversification in these bottlebrush corals was a shift in the trajectory of the ACC to north of New Zealand around the Middle Miocene [36]. This event likely allowed certain Antarctic organisms to disperse northward via the Macquarie Ridge, as hypothesized for notothenid fishes [36]. Taking into account the limited dispersal potential of brooding octocorals [37], the Macquarie Ridge may have also been the route connecting southern and northern populations of primnoid bottlebrush octocorals (Fig. 2b). During the Early Pliocene the ACC returned to its original position [36], and even though Antarctica and the Macquarie Ridge had already split, this new placement of the ACC between the respective populations could have helped sustaining the isolation of the northern populations. This shift southward may have allowed further diversification of the northern populations under different oceanographic regimes.

During the Middle Miocene, changes in the trajectories and intensities of oceanic currents were common and affected worldwide oceanographic patterns [38, 39]. As for the primnoid bottlebrush octocorals, these changes also had a great effect on the diversification of other corals and deep-sea dwellers. For example, the pattern of dispersal for the deep-sea octocoral Paragorgia arborea matches the Miocene ocean circulation model [35]. The deep-sea shrimp of the family Bresiliidae inhabit hydrothermal vents and hydrocarbon seeps, and their probable time of radiation has been placed in 
the Miocene around $20 \mathrm{Ma}$ [40]. Moreover, during the Middle Miocene, between 13 and $16 \mathrm{Ma}$, there was a faunal exchange in foraminiferans involving extinction and speciation events, and changes in species' distributional patterns [41]. All these changes during the Middle Miocene were probably associated with shifts in strength, chemical and physical properties of water masses, and the reorganizations of intermediate and deep ocean circulation that occurred as a result of the Antarctic glacial expansion [41-44]. Therefore it is not surprising that the diversification of the Southern Ocean and Southern Pacific primnoid bottlebrush octocorals took place at this time.

Time estimates, as the ones presented here, should be treated with caution whenever there are few strong calibration points [45]. We consider that using fossils from taxa that are closely related to Primnoidae would give a more reliable estimate of divergence time and, although increasing the number of calibration points would improve the precision of the divergence time estimates [46], no additional fossils with strong paleontological evidence were available. Two other studies have tried to estimate diversification times in primnoid octocorals $[47,48]$, but used older fossils that are more distantly related to Primnoidae or are unclear in their phylogenetic placement [49]. Using older fossils such as the ones employed in previous studies would have clearly pushed back the diversification time estimates in bottlebrush octocorals, an outcome that could also be expected if older fossils are found for Keratoisidinae or even for Primnoidae. The consequences that new fossils may bring on the diversification estimates presented here are uncertain, as with any other study that relies on calibration methods, hence the caution in using and interpreting the dates. However, we consider our estimates to be robust given our fossil selection and the priors used on this fossil (see Methods).

\section{Biodiversity implications}

Genetic analyses clearly showed substantial population structure, often with monophyletic regional assemblages. These two results may support a case of cryptic speciation, but further taxonomical evaluation is needed. Due to recent migration events, some clades exhibit sympatry, as is the case of New Zealand and the Macquarie Ridge, where there is no apparent ecological split, at least in terms of depth. Additional information regarding the ecological preferences for each population would aid in further taxonomical classification, however such studies are methodologically challenging given the depth of the study sites. Currently, we rely on morphological characters from the whole colony, polyps, and sclerites to define and distinguish octocoral species [50]. Based on preliminary gross morphological analyses of the colonies, we have found differences in branching pattern and colour (Fig. 1). However at a microscopic level, we observe differential texture of the opercular scales, i.e., the sclerites that cover the tentacles of the polyps when retracted.

As previously mentioned, amongst the Antarctic population there are colonies that have the characters of Tokoprymno maia and others that resemble Thouarella. The general colony branching pattern of those resembling Thouarella is like that of Tokoprymno, while the polyp form and the shape and arrangement of the sclerites clearly suggest the samples belong to the species Thouarella viridis (apart from the colour of the colony and the absence of ridges on the coenenchymal sclerites). Thouarella is also a deep-sea brooding primnoid octocoral [37], which is commonly found in the Southern Ocean at depths around $400 \mathrm{~m}$ [51]. Some species of Thouarella share with the genus Tokoprymno the bottlebrush colony shape, polyps arranged singly, and the presence of a keel on the opercular scales [52]. Until recently, one of the major characters used to distinguish these two genera was the inclination or folding of the marginals over the bases of the operculars [37], but Taylor et al. [51] showed this is a species-specific character present in Thouarella, and many species have the marginals standing straight up or extensively flared, trumpet-like. Another character is that in Thouarella spp. the polyps are often angled distal resulting in a shorter adaxial side bearing a smaller number of sclerites, a character generally not encountered in Tokoprymno. Further, in Thouarella the polyps commonly have too small a circumference to accommodate the 8 marginals, resulting in them becoming arranged in two series of 4. But this is not consistent and some species have more or less only one ring of marginals, as is generally the case in Tokoprymno. Additionally, Thouarella is a polyphyletic group as shown in a recent paper by Taylor and Rogers [48], where some lineages are more closely related to Tokoprymno. This recent finding corroborated the systematic closeness of these two groups and the need for further taxonomic revision.

\section{Conclusions}

This study represents the first assessment of phylogeographical patterns in deep-sea octocorals in the South Pacific and Southern Ocean. Our study system revealed that the ACC may be considered as a soft barrier, where it is possible to hypothesize recent migration. The ACC fluctuations in latitudinal positioning during the Miocene likely contributed to the diversification of these octocorals. Future analyses should include other types of genetic markers, such as microsatellites and SNPs, to more finely estimate gene flow, and evaluate possible admixture. Additional comparative phylogeographical data from different octocoral species, including both brooders and broadcast spawners, are needed to further corroborate the status of 
the ACC as a soft or filter barrier for these benthic deep-sea organisms.

\section{Methods \\ Sample collection}

We obtained dry and $96 \%$ ethanol-preserved coral tissues from the National Institute of Water and Atmospheric Research (NIWA) Invertebrate Collection, the Museum of New Zealand Te Papa Tongarewa in Wellington, New Zealand, and from the Commonwealth Scientific and Industrial Research Organization (CSIRO) in Hobart, Tasmania. The samples were collected in a series of expeditions that date from 1961 to 2010, around New Zealand, Tasmania and the Ross Sea in Antarctica (Fig. 2 and Additional file 6). All samples were collected at depths between 443 and $1712 \mathrm{~m}$ through bottom trawling (benthic sled) and bottom longline. Most samples were bycatch and only a few came from research cruises that targeted whole benthic community diversity, thus the small sample size of octocorals. Additional sequences used here as outgroups were obtained from GenBank (Additional file 6), and see below.

\section{DNA extraction, amplification and sequencing}

Using dry and ethanol preserved coral tissue, we extracted genomic DNA following a CTAB protocol [53]. After several attempts at DNA extraction, including the use of modified protocols, for some samples it was impossible to obtain high qualities and quantities of DNA. We successfully extracted DNA for 80 samples, which was resuspended in tris-ethylenediaminetetraacetic acid (TE) buffer and diluted to $20 \mathrm{ng} / \mu \mathrm{l}$ for use in PCR. Internal transcribed spacer 2 (ITS2) sequences and partial $28 \mathrm{~S}$ rDNA sequences were obtained independently. For ITS2 we used primers 5.8S-436: 5'-AGCATGTCTGTCTGAGT GTTGG-3' and 28S-663: 5'-GGGTAATCTTGCCTG ATCTGAG-3' [54], and for partial $28 \mathrm{~S}$ we used primers F635sq: 5'-CCGTCTTGAAACACGGACC-3' and R1411sq: 5'-GTTGTTACACACTCCTTAGCGG3' [55] that amplifies the D region (D2-D18) following the Saccharomyces cerevisiae LSU secondary structure model [56]. PCR profiles and primers are described in Aguilar and Sánchez [54] and Medina et al. [55], respectively. PCR products were purified using ExoSAP-IT (USB) and sent to Macrogen (Korea) where the products were Sanger-sequenced directly in both directions. Additional file 6 lists all samples, museum voucher numbers and corresponding GenBank accession numbers.

ITS2 and 28S belong to the nuclear ribosomal DNA (rDNA) marker family, which commonly consists of several tandem repeats [57]. These repeats do not evolve independently and are homogenized through a phenomenon called concerted evolution [58]. The rate of concerted evolution apparently varies among lineages of corals [59], and in some cases is high enough to completely homogenize the variation of rDNA repeats within individuals [57]. When rates of concerted evolution are slow, the number of copies within an individual could be as high as several hundred or even thousands [57, 60]. Genes belonging to the rDNA family have been widely used for corals and other marine benthic organisms in phylogenetic studies [61-64], in hybridization studies [65, 66], species delimitation purposes [61, 67, 68], and in population genetics studies $[35,69]$. In terrestrial organisms, such as plants and insects, rDNA markers have also been used for population analyses [70, 71]. The use of rDNA genes in coalescent analyses has been discussed given the possibility of high copy numbers that would reduce the detection of population structure [72]. However, some organisms exhibit no intra-genomic variation, making direct sequencing possible $[54,63,69,73]$. Assuming that no observed intra-genomic variation (as evidenced by direct sequencing) means that complete homogenization of gene copies has been achieved, coalescent analyses could be applied (with caution) to rDNA markers. This assumption has been employed several times for other anthozoans $[63,68,73,74]$. In our case, we did not find any evidence whatsoever of multiple copies of rDNA genes within individuals of the deep-sea bottlebrush octocorals, as shown by the ease of direct sequencing and clean sequence chromatograms (i.e., no background peaks).

\section{Phylogenetic analyses}

Complementary DNA chromatograms were assembled into consensus sequences using Geneious version R 8.1 (http://www.geneious.com, [75]). ITS2 and 28S DNA sequences were aligned independently using MUSCLE [76] and then concatenated for all further analyses, as these two genes are assumed to be in close physical linkage. Uncorrected p-distances were calculated in MEGA v6 [77] for each nuclear locus independently and the concatenated dataset.

Informative outgroup taxa were unavailable for both gene regions. GenBank contained data on some Tokoprymno that had ITS2 sequences but not $28 \mathrm{~S}$, and vice versa. Therefore we inferred an unrooted tree and used midpoint rooting for clearer interpretation. Topologies were inferred under the Maximum Likelihood (ML) and Bayesian Inference (BI) approaches. The optimal model of nucleotide substitution for the concatenated dataset was selected using PALM- Phylogenetic reconstruction by Automatic Likelihood Model selector [78], based on the Akaike Information Criterion (AIC). ML analyses were run under the TIMef $+\Gamma$ model with 1000 bootstrap replicates in Garli v. 2.0 [79] implemented in the Cipres Science Gateway [80]. For BI, the evolutionary model was selected using jModeltest version 2.1.4 [81] via AIC evaluating only those models implemented in 
BEAST version 1.8.2 [82]. An unpartitioned phylogenetic analysis was then run under the $\mathrm{HKY}+\Gamma$ model, consisting of 10 million Markov chain Monte Carlo generations and a burn-in of $25 \%$. Convergence and mixing were assessed using Tracer version 1.6 [83] by examining log-likelihood values across generations and ensuring that post-burn-in samples yielded an effective sample size (ESS) of $>200$ for all parameters.

\section{Phylogeographical analyses}

The concatenated sequences were used for testing panmixia among sampling sites. Accordingly, we applied the Bayes Factor approach based on a comparison of marginal likelihood ratios [84], as implemented in MIGRATE-N version 3.6 [23]. These models were evaluated by taking into account the results obtained from the phylogenetic analyses (see previous section), which showed a subdivision between samples from New Zealand into two distinct populations: New Zealand and Macquarie Ridge. The models were run allowing for full migration between localities and included the following hypotheses: I) all localities as a panmictic population; II) a three-population model that included Tasmania, New Zealand (with Macquarie Ridge) and Antarctica; III) a four-population model that included Tasmania, New Zealand, Macquarie Ridge, and Antarctica (Additional File 1). MIGRATE-N was run with four Markov chains with a static heating scheme, 50,000 recorded steps, a burn-in of 5000 across 20 independent runs. Population sizes were not constrained, and we used uniform priors for the population mutation rate $(\theta)$ and the mutation-scaled migration rate $(M)$. Given that there are no reports for nuclear mutation rates $(\mu)$ in octocorals, we used the default value. We report the log Bayes Factor (LBF) approximated by thermodynamic integration with Bézier approximation as suggested by Beerli and Palczewski [85]. As seen in the Results, the fourpopulation model was the best-supported, therefore all subsequent analyses assumed four populations (i.e., Tasmania, New Zealand, Macquarie Ridge, and Antarctica).

To visualize the relationship between the genealogy of haplotypes and geography, haplotype networks were inferred using the median joining algorithm as implemented in PopArt [86]. Patterns of genetic variation within each population were explored using a combination of tools. DnaSP v5.1 [87] was used to obtain estimates of number of haplotype (h), haplotype diversity (Hd), nucleotide diversity per site $(\pi)$ [88], and Watterson's estimator of the per-site population mutation rate $\left(\theta_{\mathrm{W}}\right)$ [89]. Genetic variation was partitioned into within- and among-population components using an analysis of molecular variance (AMOVA; [90]). The AMOVA, implemented in Arlequin 3.5.1.3 [91], evaluated a priori hierarchical groupings: I) all collecting localities as one population (i.e., no ACC barrier), and II) sub-Antarctic localities as one population compared to Antarctica (i.e., ACC as a barrier). Pairwise $F_{\mathrm{ST}}$ values [92] were calculated using DnaSP v. 5.1 to test the null hypothesis of panmixia between pairs of populations [93] with 10,000 permutations and a significance level of 0.05 .

To evaluate possible asymmetries in migration rates between population pairs, we compared eight different migration models that enforce particular patterns of spatial population genetic structure for Tasmania, New Zealand, Macquarie Ridge, and Antarctica: I) full migration model between the four localities; II) migration from West to East; III) migration from East to West; IV) migration from North to South; V) migration from South to North; VI) a stepping-stone model; VII) ACC as a complete barrier between northern and southern populations, but allowing full migration among northern populations; VIII) ACC as a barrier and stepping-stone between northern populations (Table 4). The models were run in MIGRATE-N using a Bayes Factor approach through a thermodynamic integration with the same parameters as above.

\section{Estimating divergence times}

To test whether the divergence time of southern and northern ACC populations predated the onset of the ACC, we estimated divergence times in BEAST version 1.8.2 [82]. There are no known fossils for Tokoprymno or Thouarella. Given that Isididae has been shown to be the sister clade to Primnoidae [94], for calibration purposes, we used as outgroup species (Additional file 6) seven bamboo corals from the Subfamily Keratoisidinae (Lepidisis solitaria [GenBank:FJ790910], Acanella sp. [GenBank:FJ790922], Keratoisis hikurangiensis [GenBank:FJ790941], Keratoisis projecta [GenBank:FJ790942], Acanella weberi [GenBank:FJ790943], Isidella tentaculum [GenBank:FJ790945], Keratoisis magnifica [GenBank: KT260062]), and an additional primnoid, Calyptrophora japonica [GenBank: EF090735]. As a temporal calibration constraint, we employed the oldest known fossil for the Keratoisidinae clade, i.e., Keratoisis sp. from the OtaianMiocene, dated between 21.7 and 19.0 Ma (= Keratoisis tangentis Grant 1976 in [95]). The minimum age of this fossil was treated as a minimum constraint on the age of the stem group node using a log-normal distributed prior [96]. The lognormal distribution has been considered the most appropriate for summarizing paleontological information [97]. This statistical distribution (as well as the exponential distribution) assigns a non-zero probability to node ages approaching infinity [98]. The lognormal thus accommodates much older ages albeit with diminishing prior probabilities [99, 100]. Following Ho and Phillips [97], we selected the value of the standard deviation so that $95 \%$ of the probability density lies between the minimum constraint and the oldest date of the geological 
range where the fossil was found $(21.7 \mathrm{Ma})$. This same method has been used in the diversification estimates of other deep-sea octocoral groups such as Coralliidae [101] and Callogorgia [47].

To estimate the divergence times we used only the ITS2 region, which had available outgroup sequences. Bayesian MCMC analyses assumed a Birth-Death speciation tree prior. Having previously rejected a strict clock model (results not shown), divergence times were estimated using a relaxed molecular clock with log-normal uncorrelated rates. The analysis was run under a $\mathrm{HKY}+\Gamma$ model twice to avoid searching only on local optima [102] and utilized $10^{7}$ generations and default heating values on three Metropolis-coupled chains. Trees and parameters were sampled every 1000 generations and the first $25 \%$ of the samples were discarded as burn-in. To check for adequate convergence and confirm a satisfactory effective sample size (ESS > 200), Tracer v. 1.8., LogCombiner v. 1.8, and TreeAnnotator v. 1.8 were used to combine and summarize trees files, obtain a maximum clade credibility consensus tree, and calculate $95 \%$ credibility intervals [82]. Finally we ran the analysis on an empty dataset, sampling from the prior distribution to evaluate the influence of the priors on the posterior distribution estimates $[103,104]$.

\section{Ancestral character state reconstruction}

To establish the geographic origin of this group, we reconstructed the ancestral locality taking each of the four populations (see above) as a discrete character state. The analysis used the ITS2 topology obtained from the divergence estimation (see Estimating divergence times). However, for the ease of interpretation, we removed the outgroup clade using the drop.tip function from the package 'ape' for R [105]. The analysis was based on the maximum likelihood ancestral state reconstruction method and the stochastic character mapping using the packages 'phytools' [106] and 'geiger' [107] in R. For this purpose we employed a symmetric rate model, an empirical Q matrix, and 1000 simulations.

\section{Availability of supporting data}

Sample information as museum codes and locations are provided as supporting information in the Additional file 6. DNA sequences for both gene regions can be found in GenBank and also listed in Additional file 6. 28S [GenBank: KT259907 - KT259986]; ITS2 [GenBank: KT259987 KT260067].

\section{Additional files}

Additional file 1: MIGRATE-N runs showing the log-probability of the data given the model (marginal likelihood). The runs evaluated the following migration models: I) all localities form a single panmictic population; II) three-population model; III) four-population model. The first row represents the number of parameters used for a particular model. The second row shows the symbol specification for the migration matrix given to MIGRATE-N, where and asterisk represents an estimated parameter and a zero a non-estimated parameter. The third row provides the log marginal likelihood for each model obtained by thermodynamic integration. The forth row reports the log Bayes Factor (LBF). The row 'Choice' orders the models based on the LBF, and finally, the sixth row shows the probability for each model. Populations are labelled as follows: T for Tasmania, MQ for Macquarie Ridge, NZ for New Zealand, and A for Antarctica. (DOCX $126 \mathrm{~kb}$ )

Additional file 2: MIGRATE-N output for the full model of migration between populations of the bottlebrush deep-sea octocorals. This analysis was based on 80 samples and the two nuclear genes ITS2 and $28 \mathrm{~S}$ for samples from the South Pacific and Southern Ocean. Values reported correspond to median values for the population mutation rate $(\theta)$ above the diagonal, with the mutation-scaled immigration rate $(M)$ for each direction of migration below the diagonal with source populations as rows and receiving population as columns. Values in parenthesis show the $2.5-97.5 \%$ credible interval for each reported value of $\theta$ and $M$. (DOCX $63 \mathrm{~kb}$ )

Additional file 3: Ancestral character state reconstruction for the locality of the bottlebrush octocorals through a maximum

likelihood approach. This analysis was run under a symmetric rate model using the packages 'phytools' [107] and 'geiger' [108] in R. Pie diagrams at nodes represent probabilities for each state, and the colours correspond to the localities: red for Tasmania, green for New Zealand, orange for Macquarie Ridge, and blue for Antarctica. Notice that for nodes $A, B$, and $C$ the ancestral locality reconstruction is unresolved. (DOCX $153 \mathrm{~kb}$ )

Additional file 4: Ancestral character state reconstruction for the locality of the bottlebrush octocorals through a stochastic mapping approach. This analysis was run under a symmetric rate model, an empirical Q matrix, and 1000 simulations using the packages 'phytools' [107] and 'geiger' [108] in R. The figure shows an example of nine reconstructions from a simulation of 1000 trees, where is evident the lack of resolution on the ancestral locality for node A, B, and C. The colours correspond to the localities: red for Tasmania, green for New Zealand, orange for Macquarie Ridge, and blue for Antarctica. (DOCX 319 kb)

Additional file 5: Posterior probabilities of each state at three nodes, for the ancestral character state reconstruction. Localities were reconstructed through an stochastic mapping approach. Node numbering corresponds to the same as Additional files 3 and 4 . (DOCX $40 \mathrm{~kb})$

Additional file 6: Samples used in this study. Information includes the museum code, collection locality, and GenBank accession numbers for the two nuclear gene regions. Sequences that were not obtained in this study are indicated by and asterisk $\left(^{*}\right)$. (DOCX $118 \mathrm{~kb}$ )

\section{Abbreviations}

28S: 28 S ribosomal RNA; AAIW: Antarctic Intermediate Water; ACC: Antarctic Circumpolar Current; AIC: Akaike Information Criterion; AMOVA: Analysis of Molecular Variance; BI: Bayesian Inference; Cl: Credible Interval; CSIRO: Commonwealth Scientific and Industrial Research Organization; CTAB: Cetyltrimethyl ammonium bromide; ESS: Effective Sample Size; $F_{\text {ST: }}$ F-statistic; h: number of haplotype; $\mathrm{Hd}$ : haplotype diversity; ITS2: internal transcribed spacer 2; Ka: Thousand years ago; LBF: log Bayes Factor; LGM: Last Glacial Maximum; m: immigration rate per generation; M: Mutation-scaled migration rates $(M=m / \mu)$; Ma: Million years ago; ML: Maximum Likelihood; NIWA: National Institute of Water and Atmospheric Research; PCR: Polymerase chain reaction; PF: Polar Front; SAF: Sub-Antarctic Front; SST: sea surface temperature; TE: Tris-ethylenediaminetetraacetic acid buffer; $\pi$ : nucleotide diversity per site; $\theta$ w: Watterson's estimator of the persite population mutation rate; $\mu$ : mutation rate; $\theta$ : Population mutation rate. 


\section{Authors' contributions}

LFD and JAS conceived and designed the study with help from AJC. DT provided the samples and geographic data. PA and LFD identified the samples. LFD performed the research and analysed the data. LFD wrote the article with contributions from AJC, JAS, TW, DT, and PA. All authors read and approved the final manuscript.

\section{Acknowledgments}

We would like to acknowledge Dr. Ben Sharp, Ministry for Primary Industries (MPI) and New Zealand Scientific Committee representative to the Commission for the Conservation of Antarctic Marine Living Resources (CCAMLR) for approving the provision of the coral sample data; to MPI and CCAMLR Observers for their at-sea collection of the corals. Several NIWA experts have supported this research and we acknowledge their input (Dr. Steve Parker, Dr. Sophie Mormede, Ms. Sadie Mills, Dr. Kareen Schnabel). Dr. David Bowden provided funding for molecular analyses under NIWA's Ross Sea Climate \& Ecosystem project (Ministry of Business, Innovation and Employment contract CO1X1226) and Dr. Aitana Forcen-Vazquez (NIWA) produced Fig. 2a and provided useful comments on the oceanic system for the study area. A portion of the material was obtained during the New ZealandAustralian "MacRidge 2" research voyage (TAN0803), that included the programme "Seamounts: their importance to fisheries and marine ecosystems" funded by the New Zealand Ministry for Business, Innovation, and Employment, and led by Drs. Ashely Rowden and Malcolm Clark. We are also grateful to Dr. Kirrily Moore, invertebrate collection manager, Tasmanian Museum and Art Gallery (TMAG) for the loan of specimens. We are thankful for the insightful and constructive comments from three anonymous reviewers. We would also like to acknowledge the Fondo de Investigación de la Facultad de Ciencias at the Universidad de los Andes in Bogotá, Colombia, which provided valuable funds to LFD through the Proyecto Semilla program (Convocatoria 2014-2 para la Financiación de Proyectos de Investigación Categoría: Estudiantes de Doctorado Candidatos). Additionally, we would like to thank The Systematic Association and the Lerner Gray Memorial Fund that also provided important support to LFD through The Systematics Research Fund and The Lerner Gray Grant Award programs. Tavel support to LFD was partially funded by CEMarin.

\section{Author details}

'Department of Biological Sciences, Universidad de los Andes, A.A. 4976 Bogotá, Colombia. ${ }^{2}$ Department of Animal Ecology \& Systematics, Justus Liebig University, Giessen, Germany. ${ }^{3}$ National Institute of Water and Atmospheric Research-NIWA, Wellington, New Zealand. ${ }^{4}$ Smithsonian Tropical Research Institute, Apartado, 0843-03092 Panama City, Republic of Panama. ${ }^{5} \mathrm{CSIRO}$ Marine and Atmospheric Research, PO Box 1538, Hobart, Tasmania 7001, Australia.

\section{Received: 12 September 2015 Accepted: 19 December 2015}

\section{Published online: 04 January 2016}

\section{References}

1. Brandt A, Gooday AJ, Brandao SN, Brix S, Brökeland W, Cedhagen T, et al. First insights into the biodiversity and biogeography of the Southern Ocean deep sea. Nature. 2007;447(7142):307-11.

2. Clarke A. Antarctic marine benthic diversity: patterns and processes. J Exp Mar Biol Ecol. 2008;366:48-55.

3. Griffiths HJ. Antarctic marine biodiversity - what do we know about the distribution of life in the Southern Ocean? PLoS One. 2010;5(8):e11683.

4. Krabbe K, Leese F, Mayer C, Tollrian R, Held C. Cryptic mitochondrial lineages in the widespread pycnogonid Colossendeis megalonyx Hoek, 1881 from Antarctic and Subantarctic waters. Polar Biol. 2010;33(3):281-92.

5. Clark A, Johnston NM. Antarctic marine benthic diversity. Oceanogr Mar Biol Annu Rev. 2003;41:47-114.

6. Gutt J, Sirenko BI, Smirnov IS, Arntz WE. How many macrozoobenthic species might inhabit the Antarctic shelf? Antarct Sci. 2004;16(1):11-6.

7. Barker PF, Filippelli GM, Florindo F, Martin EE, Scher HD. Onset and role of the Antarctic Circumpolar Current. Deep Sea Res II. 2007;54:2388-98.

8. Barker PF, Thomas E. Origin, signature and palaeoclimatic influence of the Antarctic Circumpolar Current. Earth Sci Rev. 2004;66:143-62.

9. Orsi AH, Whitworth III T, Nowlin Jr W. On the meridional extent and fronts of the Antarctic Circumpolar Current. Deep Sea Res I. 1995;42(5):641-73.
10. Hunter RL, Halanych KM. Evaluating connectivity in the brooding brittle star Astrotoma agassizii across the Drake Passage in the Southern Ocean. J Hered. 2008;99(2):137-48. doi:10.1093/jhered/esm119.

11. Page TJ, Linse K. More evidence of speciation and dispersal across the Antarctic Polar Front through molecular systematics of Southern Ocean Limatula (Bivalvia: Limidae). Polar Biol. 2002;25:818-26.

12. Janosik AM, Mahon AR, Halanych KM. Evolutionary history of Southern Ocean Odontaster sea star species (Odontasteridae; Asteroidea). Polar Biol. 2011;34:575-86.

13. Thornhill DJ, Mahon AR, Norenburg JL, Halanych KM. Open-ocean barriers to dispersal: a test case with the Antarctic Polar Front and the ribbon worm Parborlasia corrugatus (Nemertea: Lineidae). Mol Ecol. 2008;17:5104-17.

14. Clarke A, Barnes DKA, Hodgson DA. How isolated is Antarctica? TRENDS Ecol Evol. 2005;20(1):1-3. doi:10.1016/j.tree.2004.10.004.

15. Paz A, Ibáñez R, Lips KR, Crawford AJ. Testing the role of ecology and life history in structuring genetic variation across a landscape: A comparative ecophylogeographic approach. Mol Ecol. 2015;24(14):3723-37. doi:10.1111/mec.13275.

16. Lewis PN, Hewitt CL, Riddle M, McMinn A. Marine introductions in the Southern Ocean: an unrecognised hazard to biodiversity. Mar Pollut Bull. 2003;46:213-23.

17. Kahng SE, Benayahu Y, Lasker HR. Sexual reproduction in octocorals. Mar Ecol Prog Ser. 2011;443:265-83. doi:10.3354/meps09414.

18. Gutiérrez-Rodríquez C, Lasker H. Reproductive biology, development, and planula behavior in the Caribbean gorgonian Pseudopterogorgia elisabethae. Invertebr Biol. 2005;123:54-67.

19. Arndt A, Smith MJ. Genetic diversity and population structure in two species of sea cucumber: differing patterns according to mode of development. Mol Ecol. 1998;7:1053-64.

20. Sherman $\mathrm{CDH}$, Hunt $\mathrm{A}$, Ayre DJ. Is life history a barrier to dispersal? Contrasting patterns of genetic differentiation along an oceanographically complex coast. Biol J Linn Soc. 2008:95:106-16.

21. Bayer FM. New Primnoid gorgonians (Coelenterata:Octocorallia) from Antarctic waters. Bull Mar Sci. 1996;58(2):511-30.

22. Gray JE. Catalogue of the lithophytes or stony corals in the collection of the British Museum. London: British Museum; 1870. p. 1-51.

23. Beerli P. How to use MIGRATE or why are Markov chains montecarlo programs difficult to use? In: Bertorelle G, Bruford MW, Hauffe HC, Rizzoli A, Vernesi C, editors. Population Genetics for Animal Conservation. Cambridge: Cambridge University Press; 2009. p. 43-79.

24. Bostock HC, Barrows TT, Carter L, Chase Z, Cortese G, Dunbar GB, et al. A review of the Australian-New Zealand sector of the Southern Ocean over the last 30 ka (Aus-INTIMATE project). Quat Sci Rev. 2013;74:35-57.

25. Wong APS, Bindoff NL, Church JA. Large-scale freshening of intermediate waters in the Pacific and Indian oceans. Nature. 1999:400:440-3.

26. Lorrey AM, Vandergoes M, Almond P, Renwick J, Stephens T, Bostock H, et al. Palaeocirculation across New Zealand during the last glacial maximum at 21 ka. Quat Sci Rev. 2012;36:189-213.

27. Neil HL, Carter L, Morris MY. Thermal isolation of Campbell Plateau, New Zealand, by the Antarctic Circumpolar Current over the past $130 \mathrm{kyr}$. Paleoceanography. 2004;19(4):A4008. doi:10.1029/2003PA000975.

28. Dambach J, Thatje S, Rödder D, Basher Z, Raupach MJ. Effects of Late-Cenozoic glaciation on habitat availability in Antarctic benthic shrimps (Crustacea: Decapoda: Caridea). PLoS One. 2012;7(9):e46283. doi:10.1371/journal.pone.0046283.

29. Pyron RA, Burbrink FT. Hard and soft allopatry: physically and ecologically mediated modes of geographic speciation. J Biogeogr. 2010;37:2005-15.

30. Luiz OJ, Madin JS, Robertson DR, Rocha LA, Wirtz P, Floeter SR. Ecological traits influencing range expansion across large oceanic dispersal barriers: insights from tropical Atlantic reef fishes. Proc R Soc B Biol Sci. 2012;279(1730):1033-40. doi:10.1098/rspb.2011.1525.

31. Whitworth T, Nowlin WD, Worley SJ. The net transport of the Antarctic Circumpolar Current through Drake Passage. J Phys Oceanogr. 1982;12: 960-71.

32. Havermans C, Sonet G, d'Udekem d'Acoz C, Nagy ZT, Martin P, Brix S, et al. Genetic and morphological divergences in the cosmopolitan deep-sea amphipod Eurythenes gryllus reveal a diverse abyss and a bipolar species. PLoS One. 2013;8(9):e74218.

33. Bargelloni L, Marcato S, Zane L, Patarnello T. Mitochondrial phylogeny of Notothenioids: a molecular approach to Antarctic fish evolution and biogeography. Syst Biol. 2000;49:114-29. 
34. Rodrıguez E, Lopez-Gonzalez PJ, Gili JM. Biogeography of Antarctic sea anemones (Anthozoa, Actiniaria): What do they tell us about the origin of the Antarctic benthic fauna? Deep Sea Res II. 2007;54:1876-904.

35. Herrera S, Shank TM, Sánchez JA. Spatial and temporal patterns of genetic variation in the widespread antitropical deep-sea coral Paragorgia arborea. Mol Ecol. 2012;21(24):6053-67. doi:10.1111/mec.12074.

36. Cheng C-HC, Chen L, Near TJ, Jin Y. Functional antifreeze glycoprotein genes in temperate-water New Zealand Nototheniid fish infer an Antarctic evolutionary origin. Mol Biol Evol. 2003;20(11):1897-908. doi:10.1093/molbev/msg208.

37. Cairns SD, Bayer FM. A generic reevision and phylogenetic analysis on the Primnoidae (Cnidaria:Octocorallia). Smithson Contrib Zool. 2009;629:1-72.

38. Butzin M, Lohmann IG, Bickertl T. Miocene ocean circulation inferred from marine carbon cycle modeling combined with benthic isotope records. Paleoceanography. 2011:26:PA1203. doi:10.1029/2009PA001901.

39. Kennett JP. The Miocene Ocean: Paleoceanography and Biogeography. The Geological Society of America Inc. Boulder, Colorado; 1985.

40. Shank TM, Black MB, Halanych KM, Lutz RA, Vrijenhoek RC. Miocene radiation of deep-sea hydrothermal vent shrimp (Caridea: Bresiliidae): evidence from mitochondrial Cytochrome Oxidase Subunit I. Mol Phylogenet Evol. 1999;13(2):244-54.

41. Woodruff F. Changes in Miocene deep-sea benthic foraminiferal distribution in the Pacific Ocean: Relationship to paleoceanography. In: Kennett JP editor. The Miocene Ocean: Paleoceanography and Biogeography. The Geological Society of America: Inc; 1985. p. 131-76.

42. Tian J, Shevenell A, Wang P, Zhao Q, Li Q, Cheng X. Reorganization of pacific deep waters linked to middle Miocene Antarctic cryosphere expansion: a perspective from the South China Sea. Palaeogeogr Palaeoclimatol Palaeoecol. 2009;284:375-82.

43. Holbourn A, Kuhnt W, Frank M, Haley BA. Changes in pacific ocean circulation following the miocene onset of permanent antarctic ice cover. Earth Planet Sci Lett. 2013:365:38-50.

44. Shevenell AE, Kennett JP, Lea DW. Middle Miocene ice sheet dynamics, deep-sea temperatures, and carbon cycling: A Southern Ocean perspective. Geochem Geophys Geosyst. 2008;9(2):Q02006. doi:10.1029/ 2007GC001736.

45. Raupach MJ, Thatje S, Dambach J, Rehm P, Misof B, Leese F. Genetic homogeneity and circum-Antarctic distribution of two benthic shrimp species of the Southern Ocean, Chorismus antarcticus and Nematocarcinus lanceopes. Mar Biol. 2010;157(8):1783-97.

46. Ho SYW. The changing face of the molecular evolutionary clock. Trends Ecol Evol. 2014:29(9):496-503.

47. Quattrini AM, Georgian SE, Byrnes L, Stevens A, Falco R, Cordes EE. Niche divergence by deep-sea octocorals in the genus Callogorgia across the continental slope of the Gulf of Mexico. Mol Ecol. 2013;22(15):4123-40.

48. Taylor ML, Rogers AD. Evolutionary dynamics of a common sub-Antarctic octocoral family. Mol Phylogenet Evol. 2015;84:185-204.

49. Helm C, Schülke I. An almost complete specimen of the Late Cretaceous (Campanian) octocoral 'sis' ramosa Voigt (Gorgonacea) from the Lower Saxony Basin, northwest Germany. Cretac Res. 2003;24(1):35-40.

50. Bayer FM, Grasshoff M, Verseveldt J. Illustrated trilingual glossary of morphological and anatomical terms applied to Octocorallia. Leiden: Brill; 1983

51. Taylor ML, Cairns SD, Agnew DJ, Rogers AD. A revision of the genus Thouarella Gray, 1870 (Octocorallia: Primnoidae), including an illustrated dichotomous key, a new species description, and comments on Plumarella Gray, 1870 and Dasystenella, Versluys, 1906. Zootaxa. 2013; 3602(1):1-105

52. Zapata-Guardiola R, López-González PJ. Redescription of Thouarella brucei Thomson and Ritchie, 1906 (Cnidaria: Octocorallia: Primnoidae) and description of two new Antarctic primnoid species. Zootaxa. 2010:2616:48-68.

53. Coffroth MA, Lasker HR, Diamond ME, Bruenn JA, Berringham E. DNA fingerprints of a gorgonian coral: a method for detecting clonal structure in a vegetative species. Mar Biol. 1992;114:317-25.

54. Aguilar C, Sánchez JA. Molecular morphometrics: contribution of ITS2 sequences and predicted RNA secondary structures to octocoral systematics. Bull Mar Sci. 2007;81(3):335-49.

55. Medina M, Collins AG, Silberman JD, Sogin ML. Evaluating hypotheses of basal animal phylogeny using complete sequences of large and small subunit rRNA. Proc Natl Acad Sci U S A. 2001;98(18):9707-12.
56. De Rijk P, Van de Peer Y, Chapelle S, De Wachter R. Database on the structure of large ribosomal subunit RNA. Nucleic Acids Res. 1994;22(17):3495-501.

57. Hillis DM, Dixon MT. Ribosomal DNA: molecular evolution and phylogenetic inference. Q Rev Biol. 1991;66(4):411-46.

58. Arnheim N, Krystal M, Schmickel R, Wilson G, Ryder O, Zimmer E. Molecular evidence for genetic exchanges among ribosomal genes on nonhomologous chromosomes in man and apes. Proc Natl Acad Sci U S A Biol Sci. 1980;77(12):7323-7.

59. Wei NV, Wallace CC, Dai C-F, Pillay KRM, Chen CA. Analyses of the ribosomal Internal Transcribed Spacers (ITS) and 5.8S gene indicate that extremely high rDNA heterogeneity is a unique feature in the scleractinian coral genus Acropora (Scleractinia; Acroporidae). Zool Stud. 2006;45(3):404-18.

60. Dorado D, Sánchez JA. Internal transcribed Spacer 2 (ITS2) variation in the gorgonian coral Pseudopterogorgia bipinnata in Belize and Panama. Smithson Contrib Mar Sci. 2009;38:173-9.

61. Chen CA, Chang C-C, Wei NV, Chen C-H, Lein Y-T, Lin H-E, et al. Secondary structure and phylogenetic utility of the ribosomal Internal Transcribed Spacer 2 (ITS2) in scleractinian corals. Zool Stud. 2004;43(4):759-71.

62. Herrera S, Baco A, Sánchez JA. Molecular systematics of the bubblegum coral genera (Paragorgiidae, Octocorallia) and description of a new deep-sea species. Mol Phylogenet Evol. 2010;55:123-55.

63. Grajales A, Aguilar C, Sanchez J. Phylogenetic reconstruction using secondary structures of Internal Transcribed Spacer 2 (ITS2, rDNA): finding the molecular and morphological gap in Caribbean gorgonian corals. BMC Evol Biol. 2007;7(1):90. doi:10.1186/1471-2148-7-90.

64. Dueñas LF, Sánchez JA. Character lability in deep-sea bamboo corals (Octocorallia, Isididae, Keratoisidinae). Mar Ecol Prog Ser. 2009;397:11-23.

65. Vollmer SV, Palumbi SR. Testing the utility of Internally Transcribed Spacer sequences in coral phylogenetics. Mol Ecol. 2004;13:2763-72. doi:10.1111/j.1365-294X.2004.02265.X

66. Coleman AW, van Oppen MJH. Secondary structure of the rRNA ITS2 region reveals key evolutionary patterns in Acroporid corals. J Mol Evol. 2008;67:389-96.

67. Forsman ZH, Barshis DJ, Hunter $\mathrm{CL}$, Toonen RJ. Shape-shifting corals: molecular markers show morphology is evolutionarily plastic in Porites. BMC Evol Biol. 2009:9(1):45. doi:10.1186/1471-2148-9-45.

68. Yasuda N, Taquet C, Nagai S, Fortes M, Fan T-Y, Harii S, et al. Genetic diversity, paraphyly and incomplete lineage sorting of mtDNA, ITS2 and microsatellite flanking region in closely related Heliopora species (Octocorallia). Mol Phylogenet Evol. 2015;93:161-71.

69. Baird HP, Miller KJ, Stark JS. Evidence of hidden biodiversity, ongoing speciation and diverse patterns of genetic structure in giant Antarctic amphipods. Mol Ecol. 2011;20(16):3439-54.

70. Grundmann M, Ansell SW, Russell SJ, Koch MA, Vogel JC. Genetic structure of the widespread and common Mediterranean bryophyte Pleurochaete squarrosa (Brid.) Lindb. (Pottiaceae)- evidence from nuclear and plastidic DNA sequence variation and allozymes. Mol Ecol. 2007:16(4):709-22.

71. Oh HK, Yoon HJ, Kim MJ, Jeong HU, Kim SR, Hwang JS, et al. ITS2 ribosomal DNA sequence variation of the bumblebee, Bombus ardens (Hymenoptera: Apidae). Genes Genomics. 2009;31(4):293-303

72. Prada C, DeBiasse MB, Neigel JE, Yednock B, Stake JL, Forsman ZH, et al. Genetic species delineation among branching Caribbean Porites corals. Coral Reefs. 2014:33(4):1019-30. doi:10.1007/s00338-014-1179-5.

73. Aguilar C, Sánchez JA. Phylogenetic hypothesis of gorgoniid octocorals according to ITS2 and their predicted RNA secondary structures. Mol Phylogenet Evol. 2007:43(3):774-86. doi:10.1016/j.ympev.2006.11.005.

74. Medina M, Weil E, Szmant AM. Examination of the Montastraea annularis species complex (Cnidaria: Scleractinia) using ITS and COI sequences. Mar Biotechnol. 1999;1:89-97.

75. Kearse M, Moir R, Wilson A, Stones-Havas S, Cheung M, Sturrock S, et al. Geneious Basic: an integrated and extendable desktop software platform for the organization and analysis of sequence data. Bioinformatics. 2012;28(12):1647-9.

76. Edgar R. MUSCLE: multiple sequence alignment with high accuracy and high throughput. Nucleic Acids Res. 2004;32(5):1792-7.

77. Tamura K, Stecher G, Peterson D, Filipski A, Kumar S. MEGA6: molecular evolutionary genetics analysis version 6.0. Mol Biol Evol. 2013;30(12):2725-9.

78. Guindon S, Delsuc F, Dufayard J-F, Gascuel O. Estimating maximum likelihood phylogenies with PhyML. In: Posada D, editor. Bioinformatics for DNA Sequence Analysis. Methods in Molecular Biology. New York City: Humana Press; 2009. p. 113-37. 
79. Zwickl DJ. Genetic algorithm approaches for the phylogenetic analysis of large biological sequence datasets under the maximum likelihood criterion. Austin: The University of Texas at Austin; 2006.

80. Miller MA, Pfeiffer W, Schwartz T. Creating the CIPRES Science Gateway for inference of large phylogenetic trees, Proceedings of the Gateway Computing Environments Workshop (GCE). New Orleans: IEEE; 2010.

81. Darriba D, Taboada GL, Doallo R, Posada D. jModelTest 2: more models, new heuristics and parallel computing. Nat Methods. 2012;9(8):722.

82. Drummond AJ, Suchard MA, Xie D, Rambaut A. Bayesian phylogenetics with BEAUti and the BEAST 1.7. Mol Biol Evol. 2012;29:1969-73.

83. Rambaut A, Drummond AJ. Tracer v.1.4. 2007. http://beast.bio.ed.ac.uk/Tracer. Accessed Nov 2007.

84. Kass RE, Raftery AE. Bayes Factors. J Am Stat Assoc. 1995;90(430):773-95.

85. Beerli P, Palczewski M. Unified framework to evaluate panmixia and migration direction among multiple sampling locations. Genetics. 2010;185:313-26.

86. Leigh JW, Bryant D. POPART: full-feature software for haplotype network construction. Methods Ecol Evol. 2015;6(9):1110-6. doi:10.1111/2041-210X.12410.

87. Librado P, Rozas J. DnaSP v5: a software for comprehensive analysis of DNA polymorphism data. Bioinformatics. 2009;25(11):1451-2. doi:10.1093/bioinformatics/btp187.

88. Nei M, Li WH. Mathematical model for studying genetic variation in terms of restriction endonucleases. Proc Natl Acad Sci. 1979;76(10):5269-73.

89. Watterson GA. On the number of segregating sites in genetical models without recombination. Theor Popul Biol. 1975;7(2):256-76.

90. Excoffier L, Smouse PE, Quattro JM. Analysis of molecular variance inferred from metric distances among DNA haplotypes: Application to human mitochondrial DNA restriction data. Genetics. 1992;131:479-91.

91. Excoffier $L$, Lischer HEL. Arlequin suite ver 3.5: a new series of programs to perform population genetics analyses under Linux and Windows. Mol Ecol Resour. 2010;10(3):564-7. doi:10.1111/j.1755-0998.2010.02847.x.

92. Lynch M, Crease TJ. The analysis of population survey data on DNA sequence variation. Mol Biol Evol. 1990;7(4):377-94.

93. Raymond M, Rousset F. An Exact Test for Population Differentiation. Evolution. 1995:49(6):1280-3. doi:10.2307/2410454.

94. McFadden CS, France SC, Sánchez JA, Alderslade P. A molecular phylogenetic analysis of the Octocorallia (Cnidaria: Anthozoa) based on mitochondrial protein-coding sequences. Mol Phylogenet Evol. 2006;41:513-27.

95. Hayward BW. Lower Miocene corals from the Waitakere Ranges, North Auckland, New Zealand. J R Soc N Z. 1977;7(1):99-111.

96. Ho SYW. Calibrating molecular estimates of substitution rates and divergence times in birds. J Avian Biol. 2007;38:409-14.

97. Ho SYW, Phillips MJ. Accounting for calibration uncertainty in phylogenetic estimation of evolutionary divergence times. Syst Biol. 2009;58(3):367-80. doi:10.1093/sysbio/syp035.

98. Heath TA. A hierarchical Bayesian model for calibrating estimates of species divergence times. Syst Biol. 2012;61(5):793-809.

99. Nowak MD, Smith AB, Simpson C, Zwickl DJ. A simple method for estimating informative node age priors for the fossil calibration of molecular divergence time analyses. PLoS One. 2013;8(6):e66245. doi:10.1371/journal.pone.0066245.

100. Donoghue PCJ, Benton MJ. Rocks and clocks: calibrating the Tree of Life using fossils and molecules. Trends Ecol Evol. 2007;22(8):424-31.

101. Ardila NE, Giribet G, Sánchez JA. A time-calibrated molecular phylogeny of the precious corals: reconciling discrepancies in the taxonomic classification and insights into their evolutionary history. BMC Evol Biol. 2012;12:246. doi:10.1186/1471-2148-12-246.

102. McGuire JA, Witt CC, Remsen JV, Corl A, Rabosky DL, Altshuler DL, et al. Molecular phylogenetics and the diversification of hummingbirds. Curr Biol. 2014;24:910-6.

103. Thorne $J$, Kishino $H$. Divergence time and evolutionary rate estimation with multilocus data. Syst Biol. 2002;51(5):689-702.

104. Wood HM, Matzke NJ, Gillespie RG, Griswold CE. Treating fossils as terminal taxa in divergence time estimation reveals ancient vicariance patterns in the Palpimanoid spiders. Syst Biol. 2013;62(2):264-84

105. Paradis E, Claude J, Strimmer K. APE: analyses of phylogenetics and evolution in R language. Bioinformatics. 2004;20(2):289-90.

106. Revell LJ. Phytools: An R package for phylogenetic comparative biology (and other things). Methods Ecol Evol. 2012;3:217-23.
107. Harmon LJ, Weir JT, Brock CD, Glor RE, Challenger W. GEIGER: investigating evolutionary radiations. Bioinformatics. 2008:24:129-31.

108. Sokolov S, Rintoul SR. Circumpolar structure and distribution of the Antarctic Circumpolar Current fronts: Variability and relationship to sea surface height. Journal of Geophysical Research. 2009;114:C11019. doi:10. 1029/2008JC005248

\section{Submit your next manuscript to BioMed Central and we will help you at every step:}

- We accept pre-submission inquiries

- Our selector tool helps you to find the most relevant journal

- We provide round the clock customer support

- Convenient online submission

- Thorough peer review

- Inclusion in PubMed and all major indexing services

- Maximum visibility for your research

Submit your manuscript at www.biomedcentral.com/submit

) Biomed Central 